\title{
Facebook as a Means of Promotion of Tourist Agencies Specialized for Youth Travel in Croatia and Serbia
}

Iva Slivar*

Received: May 2009 | Accepted: August 2009

\begin{abstract}
Social media are a trend and one of the most researched topics lately. The aim of the paper is to stress the need for all tourist companies to enter the world of social networks, the hottest online hobby of young people, especially those operating in the youth niche. Marketers are still searching for ways to commercially exploit social networks potentials and as a result they are still holding back and sticking to well known promotion models. The goal of the paper is to explore new models of promotion social networks offer as a young communication channel in tourism, based on the Facebook case.
\end{abstract}

Key words: Facebook, social network sites, tourist agencies, youth travel

\section{Introduction}

Social media also referred as User Generated Content (UGC) or Consumer Generated Media (CGM) is all information content (blogs, online reviews, wikis etc.) created by people using highly accessible publishing technologies (http://en.wikipedia.org/wiki/Social_ media). Social software includes a large number of tools used for online communication, for instance: Instant messaging, text chat, weblog, wikies, social network services, social guides, social bookmarking, social citations, social libraries and virtual words (Warr, 2008). Social network sites (SNSs) like Facebook, MySpace, Twitter, LinkedIn or Bebo are as webbased services that allow individuals to (1) construct a public or semi-public profile within a bounded system, (2) articulate a list of other users with whom they share a connection, and (3) view and traverse their list of connections and those made by others within the system. The nature and nomenclature of these connections may vary from site to site. While their key technological features are fairly consistent, the cultures that emerge around SNSs are varied (Boyd, Ellison, 2007).

According to Jupiter research when it comes to reserving accommodation, user generated content was cited to be more influential than brand: $36 \%$ of those surveyed found UGC (par-

* Online marketing coordinator, Rovinj, iva.slivar@maistra.hr 
ticularly online reviews) influenced their hotel selection the most in comparison to $21 \%$ the brand or reputation of the hotel. It also found that in just 3 years time over $70 \%$ of all web content will be user-generated (http://blog.highlandbusinessresearch.com/2008/o6/12/travel-2Othe-data-impacts-and-business-implications/). The key question is how can tourist companies turn this new phenomenon to their advantage?

\section{What is Facebook?}

Facebook was founded by the Harvard student Mark Zuckerberg on February 4, 2004. On September 11, 2006 this network became open for public. Today Facebook counts 80 million active members (visiting the page at least once a month) (http://en.wikipedia.org/wiki/Facebook). Anyone of ages thirteen and over can join Facebook and use it for free. Facebook offers around fifteen language variations and is currently being translated into Croatian. After joining the network, the new member creates a personal profile choosing the level of information that he or she is willing to reveal and in addition, using privacy settings, one can restrict the level of personal information making them accessible only to specific users or groups of users within his/her network (only members of a certain network are able to see profiles within their network). The fact that the majority of users sign up with their true identities has contributed to Facebook success. The purpose of this social network site is to locate and communicate with people one knows but has lost contact with. Facebook also offers the possibility to meet new people. In order to add friends to a friends' list, it is necessary to send an invitation of friendship that the given person should confirm or to accept someone else's friendship request. Distinctive features of Facebbok are modules known as applications (Boyd, Ellison, 2007). Among the most popular are Superwall and Funwall which display all the content of a profile. There are numerous different applications available: tests, competitions, different games that can be played online in groups, gift applications, etc. The latter are a great source of promotion of world famous product brands. According to Alexa, Facebook is now ranking as the forth most visited website in the world (after Google.com, Yahoo and You Tube). It has recently surpassed MySpace, which makes it the most popular social network service on a global level counting 55 ooo networks. Internet users aged between 16 and 24 are the most likely group to use Facebook and the fastest-growing demographic group is those aged 25 years and above (http://www.blogher.com/node/11487 according to Comscore, http://www.facebook.com/press/info.php?statistics).

According to Cassidy, the site is tightly integrated into the daily media practices of its users: the typical user spends about 20 minutes a day on the site, and two-thirds of users log in at least once a day (Ellison, et al. 2007).

\section{Facebook Business Pages and Groups}

Since the primary purpose of Facebook is socialization, it makes it unrealistic to expect direct sales from such promotion, but rather expansion of brand awareness. Benefits of creating a Facebook page are numerous:

- Direct contact with users (mostly young people who use their real identity) and also with prospective employees;

- Possibility of user segmentation; 
- Loyalty of Facebook users and expansion of the network on the market;

- Possibility of transparent feedback collection;

- Minimum marketing costs since creating a page is free of charge and administrating does not require any specific knowledge;

- Access to statistics counting the number of visitors to the site;

- Possibility of creating a link on the official site but with no SEO ${ }^{1}$ value;

- Possibility for fans to upload photos or video content;

- Facebook pages get indexed by Google;

- "Free ads" automatically appear on Facebook profiles of friends showing the name of the page and sending an invitation to become fans.

Learn more about creating a Facebook page at the following link: http://www.facebook. com/business/?pages. Recently Facebook has upgraded its pages: pages now act like profiles showing its visitors all posts. New wall settings and mobile features (allowing posts to be added from mobile devices) have been added. Facebook pages do not offer the possibility of presentation on more than one page which will probably be possible in an upgraded version. Facebook also offers the possibility of creating groups. Information about how to create groups can be found at http://www.wikihow.com/Create-a-New-Facebook-Group. Facebook groups have members not fans. Unlike Facebook pages which are indexed, Google does not index group pages but opens a Facebook group directory which can be browsed alphabetically. Beside those, benefits of Facebook pages are applicable to groups.

When communicating on Facebook it should be kept in mind that the audience is extremely media-sensitive and fed up with typical marketing stories of grandeur and superlatives. The style of company presentation should therefore be less formal since otherwise it is likely to produce a counterproductive effect - publicly available.

\section{Suggestions for Creating Facebook Applications for Tourist Agencies for Youth Travel}

Creating an application on Facebook require some programming skills and individual hosting services since Facebook does not offer the possibility of hosting on its server ${ }^{2}$. Applications can be uploaded on Facebook pages of the tourist company and may enter the endless list of all Facebook applications.

An interesting idea is an application that functions as a "news feed" which offers special opportunities and discounts for users who install it. These types of applications can be divided into categories such as: news, special opportunities, employment or as a source of information for those who already booked their holiday. This application works as a newsletter or support and is presented in a new form.

For those with limited budget, it is possible to create a Facebook application in the form of a test: the company famfamfam.com created an application called "Quiz creator" which enables users to create their own tests using different questions, possible answers and solutions. Quick

1 Search Engine Optimisation (SEO) includes all tactics and strategies in order to gain better ranking of web sites on web search engines like Google, when searched by certain keywords. Links from Facebook receive a no follow attribute which makes them not valuable in terms of SEO.

2 For more information on how to create a Facebook application please visit: http://www.digital-web.com/articles/ building_facebook_applications/ 
application creator is available at the following link: http://www.facebook.com/add.php?api key=6ff7e186d2402b69fo1b805a5fao1do5\&next=http\% 3A\% 2F\% 2F\% 2Fquiz. Like other Facebook application, the test application is also installed on users' profiles and requires filling out a request form (no programming knowledge required). The test has to be fun and intriguing.

\section{Facebook Ads as a Means of Recruitment of Personnel and as a Marketing Tool}

Facebook free ads platform for users offers the possibility to find employees to all, even those who do not have their own pages or applications. Setting a small ad for a job is free of charge and ads are listed in different job categories. It is also possible to have listings for vacation rentals or last minute travel deals and similar offers.

Link to ads for the Croatian network is: http://www.facebook.com/marketplace/index. php?f=67109227\&b=67109227 and for the Serbian (retrieved from Croatia):

http://apps.facebook.com/marketplace/searchapp/?s=createtime\&c=job\&country=SRB.

Facebook also offers many different opportunities for advertising (three types of ads are available: classic, social and interactive) and the ads are displayed on users' profiles. The advantage of advertising on Facebook is good market segmentation. For more information please visit: http://www.facebook.com/ads/?src=advf2. Some popular applications require payment or offer the alternative to show ads in order to run for free. One such application, created as an online game is Geo challenge where tourist agencies and similar companies are welcome to advertise.

\section{Research on the Use of Facebook Pages and Groups for Promotion of Tourist Agencies Specialized for Youth Travel}

On May 16, 2009 a research on the presence of tourist agencies for Youth travel was conducted on Facebook Croatia and Serbia. The list of travel agencies is available online by national associations of tourist agencies: UHPA in Croatia and YUTA in Serbia. The membership in those associations is voluntary based. This fact frames the limits of the research itself meaning that agencies which are not members of the above associations were not included in the research. Niche of business was filtered online on official web sites of UHPA and YATA in order to get lists of tourist agencies which offer travel for young people. In Croatia there are 105 agencies which are registered to be offering travel arrangements for Youth retrieved from: http://www. putovanja.hr/index.jsp and in Serbia 127 according to: http://www.yuta.rs/sr/yuta/members. asp input $=17 \&$ nItems $=1000 \&$ details $=0$ \& clause $=3 \&$ result $=1 \&$ sortorder $=1 \&$ nlist $=1000 \&$ vlist $=0$ \&NAV $=$.

The methodology of the research consisted of brand name search using Facebook's internal search engine.

The results showed that only two tourist agencies specialized for youth travel operating in Croatia have their presence on Facebook: Grand Tours with a closed group ( members must be invited or approved by an admin) and Katarina Line featuring two groups: one for cruises and a staff group. Grand Tours presence on Facebook is useless since closed types of groups are restricting voluntary membership therefore users aren't allowed to join without administrators permission. None of the active travel agencies in Youth sector in Croatia have a Facebook page. Searching for Generalturist's Facebook presence one group showed up: "I love ski- 
ing 2008/o9", created by a Facebook user who suggested, among other links, Generalturist as a good reference web site for skiing.

In Serbia, three tourist agencies specialized in the youth travel niche have their own Facebook pages: Adriatic-Pan Europa, Amigo Travel and Globus Tours. None of the 127 agencies has its own group that can be related to its corporation although a Facebook user created a group about an excursion to Spain related to the Grand TT agency.

\section{Conclusion}

Social media are a new expanding phenomena influencing travelers choice and therefore should be included in promotional campaigns. This paper only frames a starting point for tourist companies in order to enter one social network.

The social network Facebook is a platform for socializing, renewing old friendships and meeting new people. Tourist agencies as well as other tourist companies are advised to create their own business Facebook pages or travel focused groups for promotion purposes, designing applications such as "news feed". Those with limited budget can do it for free: open a page or a group, create at least one application (in the form of a test) and place ads for a job and special promotions. It is important to keep in mind that Facebook is a medium that requires a user friendly approach.

Research has shown that both Serbian and especially Croatian tourist agencies specialized in the youth niche are still poorly aware of the need for promotion on the Facebook. Although in Croatia there are three active groups on Facebook created by tourist agencies specialized for youth travel, only one, Katarina Line Cruises (oriented only to the cruise segment) is actually suitable for users to join. Unlike their Croatian colleagues, Serbian tourist agencies have chosen Facebook pages as a mean of promotion on this social network featuring three pages from the following agencies: Adriatic-Pan Europa, Amigo Travel and Globus Tours.

It will be interesting to see in what direction will other tourist agencies focus their efforts: will there be more business pages in Serbia and more groups in Croatia? Will new entries follow pioneers? Other suggestions for research should focus on the influence of Facebook in youth travel decisions and qualitative analyses of corporate communication, and wider, analyses of tourist companies and UGC: how many tourist companies in the region have developed a social media plan and what sites, tools and activities it includes.

\section{References}

Boyd, D.M., Ellison, N. B., 2007. Social network sites: Definition, history, and scholarship. Journal of Computer-Mediated Communication 13(1), article 11. retrived from: http://jcmc.indiana.edu/vol13/issue1/boyd.ellison.html (24.4.2009.)

Ellison, B. et al., 2007. The benefits of Facebook "friends:" Social capital and college students' use of online social network sites. Journal of Computer-Mediated Communication 12(4), article 1., retrived from: http://jcmc.indiana.edu/vol12/issue4/ellison.html (24.4.2009.)

Gross, R., et al., (2005): Information revelation and privacy in online social networks, III Proceedings of the 2005 ACM workshop on Privacy in the electronic society, Alexandria, VA, USA [doi>10.1145/1102199.1102214] (19.10.2008.)

http://cpmadvisors.com/2008/facebook-us-user-average-age-now-2296/ (4.2.2008.) 
http://en.wikipedia.org/wiki/Facebook (1.2.2008.)

http://en.wikipedia.org/wiki/Social_media (1.2.2008.)

http://www.alexa.com/topsites (19.5.2009.)

http://www.allfacebook.com/2007/10/facebook-secretly-reveals-demographic-data/ (12.1.2008.)

http://www.blogher.com/node/11487 (12.1.2008.)

http://www.comscore.com/press/release.asp?press=1519 (15.1.2008.)

http://www.facebook.com (13.1.2008.)

http://www.wikihow.com/Create-a-New-Facebook-Group. (4.2.2008.)

http://blog.highlandbusinessresearch.com/2008/o6/12/travel-20-the-data-impacts-and-business-implications/ (19.5.2009.)

Warr, W. A. (2008): „Social software: fun and games or business tools?"Journal of Information Science 2008; 34;591; originally published online Jun 13, 2008, retrived from: http://jis. sagepub.com/cgi/content/abstract/34/4/591 (19.10.2008.) 